\title{
Adorno: Educação e Emancipação
}

Nildo Viana (1)

Resumo: Para Adorno, a educação deve, simultaneamente, evitar a barbárie e buscar a emancipação humana. Ele questiona a educação autoritária e pensa uma educação emancipatória, mas, ao não apresentar um projeto de transformação social global, deixa de lado uma compreensão da totalidade da sociedade repressiva e realiza um isolamento do processo educacional, atribuindo a ele um papel transformador que dificilmente pode realizar isoladamente.

Na história do pensamento educacional contemporâneo, Theodor Adorno é um nome de destaque. Nosso objetivo no presente texto é expor a concepção de educação de Adorno de forma crítica, visando resgatar, simultaneamente, suas contribuições e seus limites.

Adorno analisa a educação a partir dos conceitos de barbárie e emancipação (Adorno, 1995). Ele tem como preocupação fundamental a questão da barbárie. Adorno define a barbárie da seguinte forma:

"Suspeito que a barbárie existe em toda a parte em que há uma regressão à violência física primitiva, sem que haja uma vinculação transparente com objetivos racionais na sociedade, onde exista portanto a identificação com a erupção da violência física. Por outro lado, em circunstâncias em que a violência conduz inclusive a situaçóes bem constrangedoras em contextos transparentes para a geração de condições humanas mais dignas, a violência não pode sem mais nem menos ser condenada como barbárie" (Adorno, 1995, p. 159-160).

Adorno identifica barbárie e nazismo, pois este seria um caso de manifestação da barbárie. Durante o nazismo, a violência física se torna algo banal, e as pessoas passam a se identificar com ela, mesmo ela estando desvinculada de objetivos racionais.

O papel da educação, tal como visto por Adorno, é impedir a volta da barbárie, isto é, o retorno do totalitarismo, do nazismo. Este retorno é uma possibilidade existente e é justamente por pensar assim que a preocupação de Adorno se centra na questão da barbárie. As condições histórico-sociais que engendraram o nazismo ainda existem e por isso é preciso impedir o seu ressurgimento. Se a possibilidade do retorno da barbárie existe, então a educação assume um papel importante no sentido de prevenir e impedir tal retorno. A preocupação de Adorno é em evitar a barbárie.

"Qualquer debate acerca das metas educacionais carece de significado e importância frente a essa meta: que Auschwitz não se repita. Ela foi a barbárie contra a qual se dirige toda a educação. Fala-se da ameaça de uma regressão à barbárie. Mas não se trata de uma ameaça, pois Auschwitz foi a regressão; a 
barbárie continuará existindo enquanto persistirem no que têm de fundamental as condições que geram esta regressão" (Adorno, 1995, p. 119).

A análise de Adorno mostra uma forte influência de Freud e sua concepção sobre o processo civilizatório (Freud, 1978a). Freud coloca que a civilização produz e reforça o anticivilizatório. Adorno parte desta tese e afirma que esta tese freudiana é fundamental para se realizar uma reflexão sobre Auschwitz e tentar evitar o seu retorno.

Mas, na atualidade, evitar o retorno da barbárie é extremamente difícil através da alteração dos pressupostos objetivos, que geraram e são as condições de possibilidade do nazismo. Diante deste quadro, Adorno justifica sua posição segundo a qual a ênfase deve recair sobre os aspectos subjetivos. Quais são estes aspectos subjetivos? São aqueles que remetem à psicologia dos envolvidos no holocausto, mas não nas vítimas e sim nos perseguidores:

"É preciso buscar as raízes nos perseguidores e não nas vítimas, assassinadas sob os pretextos mais mesquinhos. Torna-se necessário o que a esse respeito uma vez denominei inflexão em direção ao sujeito. É preciso reconhecer os mecanismos que tornam as pessoas capazes de cometer tais atos, é preciso revelar tais mecanismos a eles próprios, procurando impedir que se tornem novamente capazes de tais atos, na medida em que se desperta uma consciência geral acerca destes mecanismos. Os culpados são unicamente os que, desprovidos de consciência, voltaram contra aqueles o seu ódio e sua fúria agressiva. É necessário contrapor-se a uma tal ausência de consciência, é preciso evitar que as pessoas golpeiem pra os lados sem refletir a respeito de si próprias. A educação tem sentido unicamente como educação dirigida a uma auto-reflexão crítica. Contudo, na medida em que, conforme os ensinamentos da psicologia profunda, todo caráter, inclusive daqueles que mais tarde praticam crimes, forma-se na primeira infância, a educação que tem por objetivo evitar a repetição precisa se concentrar na primeira infância"(Adorno, 1995, p. 121-122).

Assim, na perspectiva de Adorno, a primeira infância assume papel primordial. Embasado na psicanálise freudiana, Adorno afirma que a formação do caráter do indivíduo ocorre durante a primeira infância. O processo civilizatório provoca uma pressão e um sentimento de claustrofobia que é exasperado num mundo administrado. Isto provoca uma busca em superar isto e a violência é uma das formas como se tenta concretizar tal "fuga da civilização".

Tendo em vista, segundo Adorno, que quanto mais intensa é a repressão, mais intensa também será a recusa da repressão, a tendência é de haver aumento da "raiva contra a civilização", e ações irracionais contra ela. A civilização gera anticivilização, um processo de integração e ao mesmo tempo de desintegração ou, como diz Adorno, "desagregação".

Porém, a violência não pode atingir a civilização em sua totalidade e por isso são eleitos alguns segmentos no seu interior e estes geralmente são os mais fracos e, 
muitas vezes, considerados (independentemente de tal consideração ser verdadeira ou falsa) felizes.

Assim, Adorno fornece grande importância ao que ele denominou "educação após Auschwitz", que teria, segundo ele, dois aspectos. Um seria a educação durante a primeira infância e o outro ao processo de esclarecimento da população, que seria um processo abrangente e geral que criaria um clima cultural e social que seria um obstáculo para a repetição da barbárie. É neste contexto que Adorno critica a tese que aponta para a necessidade de "recuperar a autoridade" ou a realização de um "compromisso", e nem se trata, também, de se limitar ao caso alemão, que pode até contribuir para a explicação do fenômeno nazista naquela época mas não tem um papel relevante para evitar o retorno da barbárie. Ao evitar estas "soluções" Adorno revela sua posição:

"O que a psicologia profunda denomina superego, a consciência moral, é substituída no contexto dos compromissos por autoridades exteriores, sem compromisso, intercambiáveis, como foi possível observar com muita nitidez também na Alemanha depois da queda do Terceiro Reich. Porém, justamente a disponibilidade em ficar do lado do poder, tomando exteriormente como norma curvar-se ao que é mais forte, constitui aquela índole dos algozes que nunca mais deve ressurgir. Por isto a recomendação dos compromissos é tão fatal. As pessoas que os assumem mais ou menos livremente são colocadas numa espécie de permanente estado de exceção de comando. O único poder efetivo contra o princípio de Auschwitz seria a autonomia, para usar expressão kantiana; o poder para a reflexão, a autodeterminação, a não-participação"(Adorno, 1995, p.124125).

No entanto, existem inúmeros obstáculos para a realização desta proposta e Adorno percebe várias delas: o campo e sua oposição à cidade, a inclinação para a violência nas grandes cidades e as pessoas com "traços sádicos reprimidos" morando nelas, bem como relações existentes em esferas sociais específicas, tal como o esporte, que produzem uma tendência para a regressão. Isto tudo está relacionado com a velha estrutura social estreitamente ligada à autoridade e ao caráter autoritário. Mas Auschwitz foi possível devido à identificação cega com o coletivo e o preparo para manipular as massas e coletivos. Trata-se da concepção tradicional de educação, voltada para a severidade, a repressão do medo e para o caráter manipulador. Adorno define o caráter manipulador, o que remete ao seu conceito clássico de consciência coisificada:

"Se fosse obrigado a resumir em uma fórmula esse tipo de caráter manipulador $3 / 4$ o que talvez seja equivocado embora útil à compreensão $3 / 4$ eu o denominaria de o tipo da consciência coisificada. No começo as pessoas deste tipo se tornam por assim dizer iguais a coisas. Em seguida, na medida em que o conseguem, tornam os outros iguais a coisas" (Adorno, 1995, p. 130).

Um exemplo oferecido por Adorno de consciência coisificada é o que ele chama de "fetichismo da técnica", que consiste numa idolatria por coisas, máquinas, em si mesmas. $\mathrm{O}$ fetichismo da técnica cria uma relação do homem com ela que contém 
algo de "exagerado, irracional, patogênico". O que possibilita isso? Para Adorno, a única explicação para isto é a incapacidade de amar. Isto não significa uma defesa sentimental e moralizante do amor, pois tal incapacidade atinge hoje a todos, com diferença de grau. Diante deste quadro, a grande questão é qual é o papel da educação. É neste contexto que Adorno distingue entre os "assassinos de gabinete" e "ideólogos", por um lado, e aqueles que executam as ações violentas. Ele pensa que contra os assassinos de gabinete e ideólogos a educação pode fazer muito pouco, ela dificilmente poderá impedir seu reaparecimento. No entanto, é possível, através da educação, impedir aqueles que executam as ações violentas de o fazêlo: os subalternos e serviçais, aqueles que assassinam outros contra seus próprios interesses, assassinando a si próprios e que assim perpetuam sua própria servidão. Esta é a forma como a educação pode cumprir com o seu papel, evitar o retorno da barbárie, o que, segundo ele, é uma questão decisiva para a sobrevivência da humanidade.

No entanto, aqui surge uma questão: é suficiente evitar a barbárie? A educação teria apenas este papel preventivo? Em seu artigo Educação Após Auschwitz esta é a abordagem, em que pese ter alguns elementos que podem abrir caminho para uma concepção mais ampla. No entanto, Adorno, em textos posteriores, avança em suas reflexões e acaba indo além de uma visão puramente preventiva da educação e passa a contemplar também a questão da emancipação. Ele enfatiza, em outros escritos, a questão da emancipação e apresenta uma visão que cria uma ligação indissolúvel entre emancipação e barbárie: promover a emancipação significa combater a barbárie, isto é, são duas faces da mesma moeda.

Não somos os primeiros a fazer este questionamento a respeito do caráter meramente preventivo da barbárie que teria a educação. Ele já foi feito, diretamente, por Helmutt Becker (veja Adorno, 1995). A resposta de Adorno é negativa, pois a educação também deve servir para o processo de emancipação. No entanto, educação para emancipação e educação contra a barbárie são uma única e a mesma coisa.

Em seu debate com Becker, posterior ao texto Educação após Auschwitz, e publicado com o título Educação para quê? Adorno aprofunda a questão da emancipação:

"A seguir, e assumindo o risco, gostaria de apresentar minha concepção inicial de educação. Evidentemente não a assim chamada modelagem de pessoas, porque não temos o direito de modelar as pessoas a partir do seu exterior; mas também não a mera transmissão de conhecimentos, cuja característica de coisa morta já foi mais do que destacada, mas a produção de uma consciência verdadeira. Isto seria inclusive da maior importância política; sua idéia [de H. Becker - NV], se é permitido dizer assim, é uma exigência política. Isto é: uma democracia com o dever de não apenas funcionar; mas operar conforme seu conceito, demanda pessoas emancipadas. Uma democracia efetiva só pode ser imaginada enquanto uma sociedade de quem é emancipado" (Adorno, 1995, p. 141-142). 
Esta idéia de emancipação, segundo Becker, seria demasiada abstrata. Adorno concorda com esta afirmação e avança dizendo que ela é o mesmo que conscientização e racionalidade, que contém, no entanto, um momento de adaptação à realidade. Isto deve ser percebido e a educação não deve evitar o reconhecimento deste momento de adaptação à realidade, pois isto a tornaria impotente e ideológica. Mas a emancipação deve ser enfatizada e por este termo Adorno compreende a visão kantiana, segundo a qual a emancipação se refere ao "homem autônomo, emancipado", seguindo a "formulação definitiva de Kant", isto é, para a "exigência de que os homens tenham que se libertar de sua autoinculpável menoridade" (Adorno, 1995, p. 141).

O homem supera a sua menoridade através da experiência e reflexão. A primeira é condição da segunda. O significado da formação é mais amplo do que a simples introjeção de valores existentes e pré-determinados pois abrange o próprio processo de superação da menoridade, que ocorre através da experiência $e$ reflexão. A experiência, enquanto categoria, nos remete ao empirismo, o contato com o objeto, e ao histórico, nos remete ao processo formativo, onde o indivíduo se torna experiente, elaborando o que o indivíduo acumula, os resultados dos processos anteriores, e o próprio processo (Maar, 1995).

A emancipação, na perspectiva de Adorno, não se refere apenas ao indivíduo como entidade isolada, mas fundamentalmente como um ser social. Ela é pressuposto da democracia e se funda na formação da vontade particular de cada um, tal como ocorre nas instituições representativas. É preciso supor, para evitar um resultado irracional, que cada um possa se servir de seu próprio entendimento. A emancipação é a formação para a autonomia, mas ela só pode ser bem sucedida se for um processo coletivo, já que na nossa sociedade a mudança individual não provoca necessariamente a mudança social mas esta é precondição daquela. A educação deve contribuir, portanto, para o processo de formação e emancipação, contribuindo para criar condições em que os indivíduos, socialmente, conquistem a autonomia.

Após esta breve descrição da concepção de educação em Adorno, podemos partir para uma reflexão crítica a seu respeito. O objetivo da educação, para Adorno, é evitar o retorno da barbárie, o que ele repete incansavelmente. Ele justifica isto devido ao fato de que as condições objetivas que geraram o nazismo permanecem $e$, por conseguinte, sua possibilidade também. O mundo burocrático, mercantil, competitivo, nos rodeia. Adorno utiliza a expressão "mundo administrado" para dar conta desta realidade. Sem dúvida, Adorno está correto. A sociedade capitalista amplia cada vez mais o processo de mercantilização e burocratização das relações sociais, bem como da competição em todas as esferas sociais, produzindo uma sociabilidade e mentalidade adequadas e reprodutoras deste processo (Viana, 2002a). A sociedade repressiva produz uma mais-repressão, que tende a desencadear energias destrutivas (Viana, 2002b).

E isto já se concretiza em certos grupos sociais, onde a violência se realiza de forma irracional e intransparente. Algumas formas de violência e o crescimento de grupos neonazistas são exemplos confirmadores disto. No entanto, falta em Adorno uma 
análise histórica mais profunda para perceber que o nazismo, especificamente, não foi um produto destas condições permanentes da sociedade capitalista. O que Adorno não percebe então é que, sendo tais condições permanentes, é preciso explicar por qual motivo o nazismo não retornou em diversas outras oportunidades

Aqui se faz necessário diferenciar possibilidade existente e possibilidade tendencial. Uma possibilidade existente é aquela que existe, isto é, é algo possível, mas sua probabilidade depende da concretização de outras possibilidades. Uma possibilidade tendencial é aquela que não só existe, mas existem forças e elementos que apontam para sua efetivação, tendo uma probabilidade maior de se efetivar, pois o curso dos acontecimentos aponta para sua realização. A possibilidade do nazismo está dada mas sua probabilidade é pequena, dependendo do contexto. Isto significa que o retorno do nazismo é uma possibilidade existente mas não tendencial. É claro que em alguns países e contextos históricos específicos, ele pode se tornar tendencial. Foi o que aconteceu na Alemanha no início do século 20 e a tendência foi prevista pelos integrantes da Escola de Frankfurt e seu estudo sobre a personalidade autoritária.

Para entender o motivo pelo qual o nazismo é possível mas se manifestou somente uma vez, na Alemanha, é necessária uma análise histórica-concreta da situação da sociedade alemã. O problema de Adorno é que, sendo alemão e tendo vivido a barbárie nazista, acabou exagerando a preocupação com o nazismo $e$ generalizando a experiência alemã para a sociedade contemporânea como um todo, ao invés de perceber o processo histórico específico que engendrou este fenômeno nesta sociedade.

Isto não quer dizer que o nazismo só pode surgir na Alemanha. Mas sim que esta sociedade reunia condições históricas e sociais que possibilitaram a emergência do nazismo. Outras sociedades, em situações análogas, geraram o fascismo ou qualquer outro tipo de ditadura. Sem dúvida, o nazismo pode surgir em outra sociedade e esta possibilidade está dada, mas a probabilidade não é tão grande quanto pensa Adorno. Sendo assim, a preocupação de Adorno é correta, retirando o exagero contido em sua análise.

Esta consideração irá intervir na análise que realizaremos da concepção adorniana dos objetivos da educação. Para que serve a educação? Para Adorno, o seu objetivo é impedir o retorno da barbárie, o que nos leva a necessidade de destruir as condições que a tornam possível. É neste contexto que Adorno apresenta a simultaneidade da luta contra a barbárie e da luta pela emancipação. A realização da emancipação é uma luta contra a barbárie, pois a primeira produz um "indivíduo autônomo" e a autonomia é o melhor antídoto contra a possibilidade de retorno da barbárie. Neste aspecto, Adorno se revela um kantiano, um representante contemporâneo da filosofia iluminista. Isto não deixa de ser espantoso. A filosofia iluminista e sua valoração da razão, da autonomia do indivíduo (Viana, 1999; Viana, 2000), é um produto histórico específico, que, embora tenha elementos que ainda podem ser aceitos hoje, em sua totalidade é uma ideologia, no sentido marxista do termo. O racionalismo por detrás da filosofia das luzes obscurece o que alguns denominariam o "irracional". 
As obras de Marx e Freud, ambos citados e influentes no pensamento de Adorno, rompem com o otimismo ingênuo do iluminismo. A razão é constituída socialmente e ligadas a interesses, valores, etc. As representações que os seres humanos criam são sociais e ligadas ao seu modo de vida e interesses e valores derivados daí, e, por conseguinte, as relações sociais determinam o processo racional (Marx, 1983; Marx \& Engels, 2002). Freud resgatou não o "irracional", visão pejorativa do que não seria o "racional", e sim o mundo do inconsciente, dos desejos reprimidos e mostrou que não existe razão pura, que esta está perpassada pelo inconsciente (Freud, 1978b).

Assim, a solução racionalista é insuficiente. Não basta a educação pregar a emancipação, buscar a autonomia do indivíduo, pois isto está, impossibilitado, a priori, pela sociedade repressiva. Adorno parece compreender isto e por isso realiza a oposição entre o subjetivo e o objetivo:

\section{"Como hoje em dia é extremamente limitada a possibilidade de mudar os} pressupostos objetivos, isto é, sociais e políticos que geram tais acontecimentos, as tentativas de se contrapor à repetição de Auschwitz são impelidas necessariamente para o lado subjetivo" (Adorno, 1995, p. 121).

Tal oposição em si é questionável. Na verdade, o "objetivo" e o "subjetivo" não são distintos, são uma unidade indissolúvel e somente no reino da ideologia é possível separá-los. A razão não pode ser separada das relações sociais. O veículo da emancipação, a educação, também não. A educação é tão coisificada quanto qualquer outro processo social. Aliás, Adorno aqui deixa de lado a categoria da totalidade, fundamental para o método marxista, e ressaltado por diversos autores (Korsch, 1977; Lukács, 1989; Kosik, 1989; Viana, 2002c). A educação é perpassada pelo mundo administrado e competitivo denunciado por Adorno.

Como seria possível, então, esta "educação para a emancipação"? Como os educadores, indivíduos com consciência coisificada, como quaisquer outros, poderiam reverter a lógica das relações sociais na escola, o peso da burocracia escolar, da competição, das relações mercantis? As crianças e os alunos em geral estão submetidos a este mundo concentracionário, carregando seus valores, reproduzindo a consciência coisificada, que é mais um obstáculo externo para uma educação emancipadora.

E mesmo que fosse possível uma tal educação emancipadora, qual efeito ela teria sobre aqueles que teriam acesso a ela? Pessoas que vivem num mundo repressivo, com as relações familiares, a mesma convivência com pessoas de consciência coisificada, com o predomínio da técnica e tecnologia, com o processo de dominação, competição, burocratização e mercantilização perpassando o conjunto das relações sociais, poderiam, apenas através do processo educativo, se emancipar? Será que uma educação voltada para a razão num mundo sem razão poderia ter algum efeito? O discurso da cooperação poderia romper com a mentalidade competitiva oriunda de uma sociedade competitiva? O discurso da igualdade e da liberdade teria efeito num mundo burocrático e autoritário em que vivemos? O discurso humanista teria eficácia na sociedade mercantil, coisificada? 
Mas isto seria um questionamento tomando a educação como sendo emancipadora, o que, na verdade, é um pressuposto questionável e o próprio Adorno, ao falar da competição nas escolas (que é apenas um dos elementos presentes nela) mostra que a escola e a educação em geral estão longe de ser emancipadoras e estão intimamente ligadas a esta sociedade repressiva, compartilhando com ela a repressão dos indivíduos.

O problema da concepção de Adorno é que ele não percebeu que a totalidade da sociedade capitalista é repressiva e que, portanto, não é possível destacar e isolar uma parte dela e atribuí-la o projeto de libertação humana. A libertação humana é um processo social que requer agentes sociais e estes estão ausentes na concepção adorniana. O curioso é que Marx, um pensador que exerceu influência sobre Adorno, não tenha sido resgatado por este para efetivar esta análise. A ausência de uma análise das relações sociais concretas, dos fundamentos da sociedade repressiva, fundada no modo de produção capitalista e na luta de classes que o caracteriza, não permite a Adorno ultrapassar uma visão ilusória do processo de emancipação humana.

Se como diz Adorno, a possibilidade da superação dos "pressupostos objetivos" é "extremamente limitada", então é necessário perceber que, devido à ligação indissolúvel entre o "subjetivo" e o "objetivo", do "lado subjetivo" a mesma dificuldade existe. A dificuldade é simultânea, pois a esfera da consciência, da cultura, da educação, tem sua gênese nas relações sociais da sociedade repressiva e, por conseguinte, traz em si a sua marca. Não há como mudar a "subjetividade" sem mudar "as condições objetivas" e vice-versa, pois na verdade, tal distinção é metafísica. Assim, o projeto de uma educação emancipadora é limitado pois não percebe a necessidade de um projeto mais amplo, englobando o conjunto das relações sociais, que é condição de possibilidade para sua concretização. A tese adorniana de que a possibilidade de mudar as "condições objetivas" é limitada é falha por não perceber que a mesma limitação se encontra nas "condições subjetivas", pois elas são da mesma natureza e estão entrelaçadas. Assim, a busca da transformação social deve atuar simultaneamente sobre as relações sociais e sobre a cultura, onde a educação possui um papel importante.

Sendo assim, a proposta de Adorno é puramente equivocada e deve ser descartada? É preciso reconhecer que existem elementos na análise de Adorno que são fundamentais para a compreensão da dinâmica da sociedade contemporânea. Sua proposta para a educação não é totalmente equivocada. Porém, é limitada e é a superação desta limitação que pode fazer com que sua proposta se torne exeqüível.

A superação desta limitação pressupõe compreender a necessidade de uma nova educação, mas ao lado disso é preciso pensar uma nova escola, novos educadores, como também transformação em diversas outras esferas sociais, tais como nas relações familiares, etc., tudo isso visando abolir as condições de possibilidade do retorno da barbárie, ou seja, abolir o conjunto das relações sociais que tornam possível o nazismo e fenômenos semelhantes. O próprio Adorno parece ter 
percepção disto quando afirma que não se trata de "pregar o amor", pois é necessário mudar a ordem social:

"Um dos grandes impulsos do cristianismo, a não ser confundido com o dogma, foi apagar a frieza que tudo penetra. Mas esta tentativa fracassou; possivelmente porque não mexeu com a ordem social que produz e reproduz a frieza" (Adorno, 1995, p. 135).

Da mesma forma, pregar a educação emancipadora para evitar a barbárie sem mexer na ordem social que a produz e reproduz levará fatalmente ao fracasso. Mas parece que Adorno não percebe isto e assim repete o mesmo erro que aponta no cristianismo. Toda e qualquer reforma puramente cultural ou intelectual está impossibilitada se não for acompanhada por mudanças nas relações sociais concretas.

A proposta de Adorno pode ser resgatada em vários aspectos, desde que de forma crítica e ampliada, englobando a educação extra-escolar, a luta política extrainstitucional, as relações de trabalho, as relações sociais nos locais de moradia e estudo, nos movimentos sociais, isto é, no conjunto das relações sociais, abarcando que Korsch denominou "totalidade histórica" e trazendo em si aquilo que Decouflé (1976) denominou "projeto revolucionário". Assim, o projeto adorniano de uma educação emancipadora ganha sentido e concreticidade, podendo contribuir com o processo de libertação humana.

\section{Referências}

Adorno , T. Educação e Emancipação. Rio de Janeiro, Paz e Terra, 1995.

Decouflé , A. Sociologia das Revoluções. São Paulo, Difel, 1976.

Freud, S. Esboço de Psicanálise. In: Col. Os Pensadores. São Paulo, Abril Cultural, 1978.

S. O Futuro de Uma Ilusão. In: Col. Os Pensadores. São Paulo, Abril

Cultural, 1978.

Korsch , K. Marxismo e Filosofia. Porto, Afrontamento, 1977.

Kosik, K. Dialética do Concreto. 4a edição, Rio de Janeiro, Paz e Terra, 1989.

Lukács , G. História e Consciência de Classe. 2a edição, Rio de Janeiro: Elfos, 1989.

Maar , W. L. À Guisa de Introdução: Adorno e a Experiência Formativa. In: Adorno, T. Educação e Emancipação. Rio de Janeiro, Paz e Terra, 1995.

Marx , Karl \& Engels, Friedrich. A Ideologia Alemã (Feuerbach). 3a edição, São Paulo, Martins Fontes, 2002. 
Marx , K. Contribuição à Crítica da Economia Política. 2a edição, São Paulo, Martins Fontes, 1983.

Viana , N. A Filosofia e Sua Sombra. Goiânia, Edições Germinal, 2000.

, N. "Cândido, de Voltaire: A Auto-Imagem do Iluminismo". Fragmentos de Cultura/UCG. Goiânia/Go., Vol. 9, no 1, jan./fev. de 1999.

N. Inconsciente Coletivo e Materialismo Histórico. Goiânia, Edições Germinal, 2002b.

, N. "Universidade e Especialização: O Ovo da Serpente". Revista Espaço

Acadêmico. Maringá/PR, ano 2, no 18, março de 2002c.

, N. "Universo Psíquico e Reprodução do Capital". In: Quinet, Antonio e outros. Psicanálise, Capitalismo e Cotidiano. Goiânia, Edições Germinal, 2002a.

(1)Professor da UEG - Universidade Estadual de Goiás; Sociólogo; Especialista em Filosofia/UCB; Mestre em Sociologia/UnB e Filosofia/UFG; Doutor em Sociologia/UnB. E-mail: nildoviana@terra.com.br 